\title{
PENGARUH KOMPENSASI DAN BUDAYA ORGANISASI TERHADAP KINERJA MELALUI KEPUASAN KERJA SEBAGAI VARIABEL INTERVENING DI YAYASAN $X$
}

\author{
Matius Sutrisno \\ Universitas Ciputra CitraLand CBD Boulevard, Surabaya, Jawa Timur, Indonesia \\ mateus_sutrisno@yahoo.com
}

Received : 26-02-2021

Revised : 22-03-2021

Accepted : 23-03-2021

\section{Abstract}

The potential possessed by each teacher does not always develop naturally due to the influence of various factors, resulting in low teacher performance. This study aims to examine the effect of compensation and organizational culture on performance through job satisfaction as an intervening variable at the $X$ Foundation simultaneously. The study population was all certified permanent teachers from Foundation X, totaling 74 teachers and a sample of 63 people through thetechnique. proportionate stratified random sampling. Collecting data using a questionnaire instrument and data analysis techniques to test the hypothesis is SEM. The results of research and discussion can be concluded that compensation has an effect on performance, compensation has a significant effect on job satisfaction, organizational culture has a significant effect on performance, organizational culture has a significant effect on job satisfaction and job satisfaction has no significant effect on performance, job satisfaction is not proven to be an intervening variable. Between the effect of compensation on performance, job satisfaction is not proven as an intervening variable between the influence of organizational culture on performance.

Keywords: compensation; organizational culture; job satisfaction; performance.

Abstrak
Potensi yang dimiliki oleh setiap guru tidak selalu
berkembang secara wajar akibat adanya pengaruh dari
berbagai faktor, sehingga berdampak pada rendahnya kinerja
guru. Penelitian ini bertujuan untuk mengkaji pengaruh
kompensasi dan budaya organisasi terhadap kinerja melalui
kepuasan kerja sebagai variabel intervening di Yayasan X
secara simultan. Populasi penelitian adalah seluruh guru
tetap yayasan X yang telah disertifikasi, yang berjumlah 74
guru dan sampel sejumlah 63 orang melalui teknik
proportionate stratified random sampling. Pengumpulan
data menggunakan instrumen kuesioner dan teknik analisis
data untuk menguji hipotesis adalah SEM. Hasil penelitian
dan pembahasan dapat ditarik kesimpulan bahwa


kompensasi berpengaruh terhadap kinerja, kompensasi berpengaruh signifikan terhadap kepuasan kerja, budaya organisasi berpengaruh signifikan terhadap kinerja, budaya organisasi berpengaruh terhadap signifikan kepuasan kerja dan kepuasan kerja tidak berpengaruh signifikan terhadap kinerja, kepuasan kerja tidak terbukti sebagai variabel intervening antara pengaruh kompensasi terhadap kinerja, kepuasan kerja tidak terbukti sebagai variabel intervening antara pengaruh budaya organisasi terhadap kinerja.

Kata kunci: kompensasi; budaya organisasi; kepuasan kerja; kinerja.

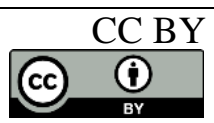

\section{PENDAHULUAN}

Yayasan X didirikan untuk ikut serta menanggapi persoalan pembangunan bangsa, khususnya berkenaan dengan masalah pendidikan dan pengajaran. Pendirian yayasan ini dilandasi oleh kesadaran dan komitmen bersama atas pembangunan bangsa, khususnya dalam pembentukan manusia Indonesia seutuhnya, antara lain diperlukan pembinaan dan pengembangan pendidikan dan pengajaran. Bahwa pembinaan dan pengembangan pendidikan dan pengajaran tersebut bukan semata-mata menjadi tanggung jawab pemerintah, tetapi juga dituntut kesadaran masyarakat untuk ikut berpartisipasi.

Mengingat pendidikan dan pengajaran merupakan elemen yang sangat penting untuk menciptakan sumber daya yang berkualitas, cerdas, damai, terbuka, demokratis dan mampu bersaing serta dapat meningkatkan kesejahteraan semua warga negara Indonesia. Kebutuhan guru yang sangat mendasar adalah kebutuhan kompensasi, dimana kompensasi masih dirasakan belum memuaskan, sangat menentukan kinerja guru. Besaran pemberian kompensasi antar unit karya berbeda-beda berdasarkan kemampuan finansial masingmasing sekolah. Maka nampaklah perbedaan nominal antara SDK, SMPK dan SMAK. Perbedaan yang cukup mencolok adalah tunjangan kelebihan mengajar dan tunjangan wali kelas. Maka hal ini menjadi permasalahan sendiri bagi kinerja yang ditunjukkan oleh tenaga pendidikan yang ada dalam yayasan ini. Guru dalam proses pembelajaran bertanggung jawab untuk melaksanakan kegiatan-kegiatan belajar guna mencapai pertumbuhan dan perkembangan yang diizinkan. Peran guru tidak hanya mentransfer pengetahuan saja, tetapi juga membentuk pribadi anak untuk mencapai kedewasaannya, karena itu guru tidak hanya berperan sebagai pengajar saja, tetapi juga sebagai pembimbing, pemimpin dan lainnya. Selain itu, guru juga dituntut berperan dalam administrasi sekolah yang meliputi administrasi kesiswaan, administrasi sarana dan prasarana, administrasi hubungan masyarakat dan layanan khusus. Tugas lain yang dibebankan oleh kepala sekolah dapat berupa piket sekolah. Guru yang profesional adalah jika pekerjaannya itu dapat menjamin kehidupan guru.

Selain itu dari hasil wawancara yang penulis lakukan dengan kepala sekolah, diperoleh informasi bahwa guru enggan mengikuti pelatihan dan seminar apabila tidak disediakan tunjangan transportasi, penginapan dan tunjangan makan selama mengikuti pelatihan. Disisi lain, kinerja guru di Yayasan X makin dituntut bekerja lebih profesional lagi, meskipun tidak dipungkiri masih ada beberapa orang guru yang semangat mengikuti pelatihan, seminar bahkan untuk melanjutkan pendidikannya ke jenjang lebih tinggi lagi. 
Masrukhin dan Waridin (2006) mengungkapkan bahwa setiap organisasi memiliki budaya organisasi yang berfungsi untuk membentuk aturan atau pedoman dalam berfikir dan bertindak dalam mencapai tujuan yang ditetapkan. Sejalan dengan Masrukhin dan Waridin yayasan menyerukan perbaikan dalam budaya organisasi dalam menanggapi temuan tim supervisi internal dengan sikap tidak perlu saling menyalahkan dan yang harus dilakukan adalah berubah. Perubahan itu adalah perubahan mental pembelajaran dan adaptif terhadap perubahan. Tekanan utama dalam perubahan dan pengembangan budaya organisasi adalah mencoba untuk mengubah nilai-nilai, sikap dan perilaku dari anggota organisasi secara keseluruhan (dan Waridin, 2006).

Berdasarkan latar belakang, maka rumusan masalah yang diteliti, yaitu apakah kompensasi kerja berpengaruh terhadap kepuasan kerja di Yayasan X, kedua apakah kompensasi kerja berpengaruh terhadap kinerja guru di Yayasan X, ketiga apakah budaya organisasi berperan terhadap kepuasan kerja di Yayasan X, keempat apakah budaya organisasi berpengaruh terhadap kinerja guru Yayasan X, kelima apakah kepuasan kerja berpengaruh terhadap kinerja guru di Yayasan X.

\section{METODE PENELITIAN}

Penelitian ini merupakan penelitian penjelasan (explanatory research) yang akan membuktikan hubungan kausal antara variabel bebas (eksogen variable) yaitu variabel variabel kompensasi dan budaya organisasi; variabel antara (intervening variable) yaitu variabel kepuasan kerja; dan variabel terikat (endogen variable) yaitu kinerja guru.

Terdapat beberapa alasan yang menjadi penyebab digunakan PLS dalam suatu penelitian. Dalam penelitian ini alasan-alasan tersebut yaitu: pertama, PLS (Partial Least Square) merupakan metode analisis data yang didasarkan asumsi sampel tidak harus besar, yaitu jumlah sampel kurang dari 100 bisa dilakukan analisis dan residual distribution. Kedua, PLS (Partial Least Square) dapat digunakan untuk menganalisis teori yang masih dikatakan lemah, karena PLS (Partial Least Square) dapat digunakan untuk prediksi. Ketiga, PLS (Partial Least Square) memungkinkan algoritma dengan menggunakan analisis series Ordinary Least Square (OLS) sehingga diperoleh efisiensi perhitungan algaritma (Ulum, Ghozali, \& Chariri, 2008). Keempat, pada pendekatan PLS, diasumsikan bahwa semua ukuran variance dapat digunakan untuk menjelaskan. Metode analisis data dalam penelitian ini terbagi menjadi dua yaitu:

Analisis deskriptif, yaitu memberikan gambaran atau deskriptif empiris atas data yang dikumpulkan dalam penelitian (Sari, 2016). Data tersebut berasal dari jawabanjawaban responden atas item-item yang terdapat dalam kuesioner dan akan dioleh dengan cara dikelompokkan dan ditabulasikan kemudian diberi penjelasan.

Menurut Sugiyono: 2018 statistik inferensial, (statistik induktif atau statistik probabilitas) adalah teknik statistik yang digunakan untuk menganalisis data sampel dan hasilnya diberlakukan untuk populasi (Jusmiana, 2020). Sesuai dengan hipotesis yang telah dirumuskan, maka dalam penelitian ini analisis data statistik inferensial diukur dengan menggunakan software SmartPLS (Partial Least Square) mulai dari pengukuran model (outer model), struktur model (inner model) dan pengujian hipotesis.

PLS (Partial Least Square) menggunakan metoda principle component analiysis dalam model pengukuran, yaitu blok ekstraksi varian untuk melihat hubungan indikator dengan konstruk latennya dengan menghitung total varian yang terdiri atas varian umum (common variance), varian spesifik (specific variance) dan varian error (error variance). Sehingga total varian menjadi tinggi.

Outer model sering juga disebut (outer relation atau measurement model) yang mendefinisikan bagaimana setiap blok indikator berhubungan dengan variabel latennya. 
Model pengukuran (outer model) digunakan untuk menilai validitas dan realibilitas model. Uji validitas dilakukan untuk mengetahui kemampuan instrumen penelitian mengukur apa yang seharusnya diukur (Cooper, Schindler, \& Sun, 2006). Sedangkan uji reliabilitas digunakan untuk mengukur konsistensi alat ukur dalam mengukur suatu konsep atau dapat juga digunakan untuk mengukur konsistensi responden dalam menjawab item pernyataan dalam kuesioner atau instrument penelitian.

\section{HASIL DAN PEMBAHASAN}

\section{Hasil}

Dalam suatu penelitian reliabilitas pada SmartPLS, ada dua perlakuan yang berbeda untuk dua jenis indikator yaitu cara untuk indikator formatif dan cara untuk indikator reflektif. Uji reliabilitas di dalam penelitian ini menggunakan indikator reflektif dan berikut cara pengukurannya. Uji reliabilitas untuk mengukur indikator reflektif dalam PLS dapat menggunakan dua metode, yaitu Cronbach's alpha dan Composite Reliability. Cronbach'alpha mengukur batas bawah nilai reliabilitas suatu konstruk sedangkan composite reliability mengukur nilai sesungguhnya reliabilitas suatu konstruk. Suatu konstruk dikatakan reliabel jika nilai Cronbach's alpha harus lebih dari 0,6 dan nilai composite reliability harus lebih dari 0,6. (Anita, Nanda, Zenita, \& Abdillah, 2018). Rule of thumbs untuk uji reliabilitas dengan indikator reflektif dapat dilihat dalam tabel 1.

Tabel 1. Ringkasan Rule of Thumb Uji Realibilitas

\begin{tabular}{|c|c|c|c|}
\hline \multirow[t]{2}{*}{ Reliabilitas } & $\begin{array}{l}\text { Cronbach's } \\
\text { Alpha }\end{array}$ & $\begin{array}{l}\text { a. }>0,70 \text { untuk Confirmatory Research } \\
\text { b. }>0.60 \text { masih dapat diterima } \\
\text { Exploratory Research }\end{array}$ & untuk \\
\hline & $\begin{array}{l}\text { Composite } \\
\text { Reliability }\end{array}$ & $\begin{array}{l}\text { a. }>0,70 \text { untuk Confirmatory Research } \\
\text { b. }>0.60 \text { masih dapat diterima } \\
\text { Exploratory Research }\end{array}$ & untuk \\
\hline
\end{tabular}

Sumber : Chin (1998) dan Ghazali (2015: 76)

Hipotesis diuji dengan menggunakan metode resampling bootstrap karena memungkinkan berlakunya data untuk terdistribusi secara bebas, tidak membutuhkan asumsi distribusi normal, dan tidak membutuhkan sampel dalam jumlah besar (minimal 30 sampel). Pengujiannya dilakukan dengan t-test. Jika hasil pengukuran pada outer model signifikan (t-stat $>1,96)$, maka indikator dapat digunakan sebagai instrumen pengukur variabel laten. Jika hasil pengukuran pada inner model signifikan ( $t$-stat $>1,96)$, maka terdapat pengaruh yang bermakna antara variabel laten.

Pengujian hipotesis mediasi dilakukan guna mengetahui kekuatan pengaruh variabel moderator pada penelitian ini, pengujian dapat dilakukan dengan menggunakan metode direct dan indirect effect, dengan membandingkan nilai path coefficients atau nilai $\mathrm{P}$ hubungan direct yang artinya tanpa melalui pengaruh variabel moderator dan hubungan indirect yang melalui pengaruh variabel moderator.

Pada hasil analisis yang tertera pada tabel diats dapat diketahui bahwa nilai tStatistik hubungan Budaya Organisasi $\left(\mathrm{X}_{1}\right)$ terhadap Kinerja $(\mathrm{Y})$ adalah 2.591. Hasil pengujian tersebut menunjukkan t-Statistik $>1,96$. Hal ini dapat diartikan bahwa Budaya Organisasi $\left(\mathrm{X}_{1)}\right.$ berpengaruh signifikan terhadap Kinerja $(\mathrm{Y})$. Hasil penelitian terbukti bahwa budaya organisasi mempunyai pengaruh positif terhadap kinerja. Budaya organisasi meliputi keterhubungan antar karyawan perusahaan termasuk rekan kerja dan 
pimpinan. Keterhubungan yang dimaksud meliputi perlunya bagi karyawan untuk memelihara hubungan yang baik dengan sesama rekan kerja, baik sesama rekan kerja pada unit yang sama maupun pada unit kerja lain.

Hasil analisis menyatakan bahwa kepuasan kerja berpengaruh tidak signifikan terhadap Kinerja guru di Yayasan X. Pengaruh yang tidak signifikan diinterprestasikan bahwa guru telah merasa puas, karena pekerjaan yang dipercayakan sebagai pelayanan dapat diselesaikan dengan baik.

\section{Pembahasan}

Metode pengambilan sampel dalam penelitian ini menggunakan purposive sampling atau judgement sampling. Menurut Sugiyono (2017:117) pengertian purposive sampling adalah teknik penentuan sampel dengan berdasarkan kriteria-kriteria atau pertimbangan tertentu (Ernanda \& Sugiyono, 2017). Adapun kriteria - kriteria penentuan sampel yang digunakan dalam penelitian ini adalah sebagai berikut :

1. Tenaga pendidik yang menjadi pegawai tetap Yayasan X.

2. Tenaga pendidik yang menjadi pegawai tetap yayasan $X$ dan telah tersertifikasi.

Berdasarkan daftar gaji yayasan $X$, tenaga pendidik tiga (3) unit karya pendidikan yayasan $\mathrm{X}$ yang telah menjadi pegawai tetap adalah 101 orang. Tenaga pendidik tersebut diseleksi kembali sesuai dengan kriteria yang sudah ditetapkan. Seleksi sampel penelitian disajikan pada tabel 2 berikut :

\section{Tabel 2. Seleksi Sampel Penelitian}

\begin{tabular}{|c|c|c|}
\hline NO & Kriteria Sampel & Jumlah \\
\hline 1. & Tenaga pendidik yang mengajar di Yayasan $\mathrm{X}$. & 101 \\
\hline 2. & $\begin{array}{l}\text { Tenaga pendidik yang menjadi pegawai tetap yayasan } \mathrm{X} \text { dan } \\
\text { belum tersertifikasi. }\end{array}$ & 21 \\
\hline 3. & Tenaga pendidik PNS yang telah tersertifikasi & 6 \\
\hline \multirow[t]{3}{*}{4.} & Tenaga pendidik yang tidak mengembalikan koesoner & 11 \\
\hline & Jumlah sampel yang diambil adalah & $101-21-6-11$ \\
\hline & Jumlah Sampel & 63 \\
\hline
\end{tabular}

Sumber: data diolah 2018

Tabel 2 menunjukkan bahwa dari 101 tenaga pendidik yang mengajar di yayasan ini dan telah tersertifikasi hanya sebanyak 80 orang yang terpilih menjadi sampel penelitian. Sehingga total pengamatan yang dilakukan dalam penelitian ini diperoleh sebanyak 80 orang. Dari 80 guru yang menjadi sampel ternyata ada 6 guru PNS yang berkarya di 2 unit karya Yayasan ini yakni 5 orang guru ada di SMPK dan 1 guru di SMAK. Sehingga sampel mengerucut menjadi 73 orang. Setelah koesioner disebar dan yang tidak dikembalikan ada 11 orang. Maka sampel yang menjadi bahan penelitian ini adalah 63 orang.

Teknik pengumpulan data merupakan cara-cara yang dilakukan untuk memperoleh data dan keterangan-keterangan yang diperlukan dalam penelitian. Teknik pengumpulan data dalam penelitian ini diharapkan dapat memberikan data yang akurat dan lebih spesifik, teknik yang digunakan dalam penelitian ini adalah menggunakan kuesioner (angket).

Kuesioner yaitu teknik pengumpulan data dengan cara menggunakan daftar pernyataan mengenai hal-hal yang berhubungan dengan variabel yang diteliti. Jenis kuesioner yang penulis gunakan adalah kuesioner tertutup, yaitu kuesioner yang sudah disediakan jawabannya, alasan penulis menggunakan kuesioner tertutup karena kuesioner 
jenis ini memberikan kemudahan kepada 86 responden dalam memberikan jawaban, kuesioner tertutup lebih praktis, dan dapat mengimbangi keterbatasan biaya dan waktu penelitian.

Instrumen penelitian yang digunakan adalah angket atau kuesioner. Kuesioner yang digunakan adalah jenis kuesioner tertutup dimana pertanyaan sudah disediakan jawabannya. Dalam penelitian ini digunakan kuesioner tertutup dengan skala Likert modelnya five point Responden adalah pendidik tetap Yayasan X, merespon tingkat persetujuan pada setiap pertanyaan kuesioner dalam kisaran sangat setuju hingga sangat tidak setuju. Adapun cara pemberian skor terhadap jawaban responden akan diberikan skor mulai 1 (satu) sampai 5 (lima). Pemberian skor terhadap alternatif jawaban yang ada dalam kuesioner sebagai berikut :

a. Sangat setuju diberi skor 5, artinya pernyataan tersebut sepenuhnya mengambarkan perasaan responden.

b. Setuju diberi skor 4 , artinya pernyataan lebih cenderung menggambarkan perasaan responden daripada tidak.

c. Netral diberi skor 3, artinya pernyataan tersebut menimbulkan rasa tidak menentu pada responden, antara menggambarkan atau tidak.

d. Tidak setuju diberi skor 2, artinya pernyataan lebih cenderung tidak menggambarkan perasaan responden daripada sebaliknya.

e. Sangat tidak setuju diberi skor 1, artinya pernyataan sama sekali tidak menggambarkan perasaan responden.

Menurut Sugiyono (2012) mendefinisikan pengertian variabel sebagai berikut : "Variabel adalah suatu atribut atau sifat atau nilai dari orang, objek atau kegiatan yang mempunyai variasi tertentu yang ditetapkan oleh peneliti untuk dipelajari atau ditarik kesimpulannya" (Parlina, 2017). Hal ini selaras dengan menurut Arikunto, "Variabel adalah obyek penelitian atau apa yang menjadi titik perhatian suatu penelitian" (Arikunto, 2019). Dalam penelitian ini terdapat tiga variabel yang akan diteliti yaitu sebagai berikut:

1. Variabel eksogen $(\mathrm{X})$ : adalah varibel yang nilainya tidak dipenaruhi/ ditentukan oleh variabel lain di dalam model. Variabel eksogen dikenal juga sebagai variabel independen (variabel bebas). Dalam penelitian ini variabel eksogen adalah Kompensasi kerja (X1) dan Budaya Organisasi (X2);

2. Variabel intervening (Z), yaitu variabel yang memberikan jeda antara variabel bebas dengan variabel terikat, sehingga variabel bebas tidak langsung mempengaruhi variabel terikat. Yang termasuk intervening variabel dalam penelitian ini adalah kepuasan kerja (Z);

3. Variabel endogen (Y), yaitu variabel yang terikat atau tergantung pada variabel lain. Dalam penelitian ini variabel endogen adalah kinerja guru (Y).

Definisi operasional adalah suatu definisi mengenai variabel yang dirumuskan berdasarkan karakteristik-karakteristik variabel tersebut yang dapat diamati (Azwar \& Abrian, 2015). Operasional variabel tentunya diperlukan untuk menentukan jenis, indikator, serta skala dari variabel-variabel yang terkait di dalam penelitian, sehingga pengujian hipotesis dengan alat bantu statistik dapat dilakukan secara benar sesuai dengan judul penelitian.

Penelitian ini menggunakan metode analisis data dengan menggunakan software SmartPLS versi 3.0. yang dijalankan dengan media komputer. Menurut Jogiyanto dan Abdillah PLS (Partial Least Square) adalah: Analisis persamaan struktural (SEM) berbasis varian yang secara simultan dapat melakukan pengujian model pengukuran sekaligus pengujian model struktural. Model pengukuran digunakan untuk uji validitas dan reabilitas, sedangkan model struktural digunakan untuk uji kausalitas (pengujian hipotesis dengan model prediksi) (Jogiyanto \& Abdillah, 2009). 
Terdapat beberapa alasan yang menjadi penyebab digunakan PLS dalam suatu penelitian. Dalam penelitian ini alasan-alasan tersebut yaitu:pertama, PLS (Partial Least Square) merupakan metode analisis data yang didasarkan asumsi sampel tidak harus besar, yaitu jumlah sampel kurang dari 100 bisa dilakukan analisis, dan residual distribution. Kedua, PLS (Partial Least Square) dapat digunakan untuk menganalisis teori yang masih dikatakan lemah, karena PLS (Partial Least Square) dapat digunakan untuk prediksi. Ketiga, PLS (Partial Least Square) memungkinkan algoritma dengan menggunakan analisis series Ordinary Least Square (OLS) sehingga diperoleh efisiensi perhitungan olgaritma. Keempat, pada pendekatan PLS, diasumsikan bahwa semua ukuran variance dapat digunakan untuk menjelaskan. Metode analisis data dalam penelitian ini terbagi menjadi dua yaitu:

PLS (Partial Least Square) menggunakan metoda principle component analiysis dalam model pengukuran, yaitu blok ekstraksi varian untuk melihat hubungan indikator dengan konstruk latennya dengan menghitung total varian yang terdiri atas varian umum (common variance), varian spesifik (specific variance), dan varian error (error variance). Sehingga total varian menjadi tinggi.

\section{KESIMPULAN}

Dari penelitian ini, maka dapat disimpulkan bahwa kompensasi mempunyai pengaruh positif terhadap kinerja. Dengan dijalankannya sistem pemberian kompensasi yang adil dan baik, maka diharapkan akan dapat mendorong karyawan organisasi untuk meningkatkan kinerjanya. Apabila sistem evaluasi kinerja pada suatu organisasi dapat menggambarkan usaha dan pekerjaan yang dilakukan oleh karyawannya dengan baik, maka akan terlihat perbedaan hasil kerja antara karyawan satu dengan yang lain. Dengan demikian karyawan akan berusaha untuk meningkatkan kinerjanya karena semakin bagus kinerjanya maka karyawan tersebut akan memperoleh imbalan kompensasi yang lebih baik dibandingkan dengan karyawan lain. Pemberian kompensasi yang tepat, sistem upah yang teratur dan rapi akan meningkatkan hasil kerja dan kinerja karyawan.

\section{BIBLIOGRAPHY}

Anita, R., Nanda, S. T., Zenita, R., \& Abdillah, M. R. (2018). Locus of Control, Penerimaan Auditor atas Dysfunctional Audit Behavior dan Intention to Quit. Jurnal Dinamika Akuntansi Dan Bisnis, 5(1), 43-54.

Arikunto, S. (2019). Prosedur penelitian.

Azwar, H., \& Abrian, Y. (2015). Pengaruh Disiplin Kerja Terhadap Kinerja Karyawan di Hotel Grand Inna Muara Padang. E-Journal Home Economic and Tourism, 9(2).

Bontis, N., Keow, W. C. C., \& Richardson, S. (2000). Intellectual capital and business performance in Malaysian industries. Journal of Intellectual Capital.

Cooper, D. R., Schindler, P. S., \& Sun, J. (2006). Business research methods (Vol. 9). Mcgraw-hill New York.

dan Waridin, M. (2006). Pengaruh Motivasi Kerja, Kepuasan Kerja, Budaya Organisasi dan Kepemimpinan terhadap Kinerja Pegawai. JurnalEkonomi Dan Bisnis, 7(2), 
197-209.

Ernanda, D., \& Sugiyono, S. (2017). Pengaruh Store Atmosphere, Hedonic Motive Dan Service Quality Terhadap Keputusan Pembelian. Jurnal Ilmu Dan Riset Manajemen (JIRM), 6(10).

Jogiyanto, H. M., \& Abdillah, W. (2009). Konsep dan aplikasi PLS (Partial Least Square) untuk penelitian empiris. BPFE Fakultas Ekonomika Dan Bisnis UGM. Yogyakarta.

Jusmiana, A. (2020). Sekapur Sirih Tentang Statistik.

Parlina, N. D. (2017). Pengaruh Perputaran Modal Kerja Terhadap Profitabilitas Melalui Perputaran Piutang Sebagai Variabel Intervening. Jurnal Inspirasi Bisnis Dan Manajemen, 1(2), 159-166.

Sari, N. P. (2016). Transformasi Pekerja Informal ke Arah Formal: Analisis Deskriptif dan Regresi Logistik. Jurnal Ekonomi Kuantitatif Terapan.

Ulum, I., Ghozali, I., \& Chariri, A. (2008). Intellectual capital dan kinerja keuangan perusahaan; Suatu analisis dengan pendekatan Partial Least Squares (PLS). 